\title{
ADHERENCE TO PHYSICAL ACTIVITY IN PEOPLE WITH TYPE 2 DIABETES
}

\author{
Carlos Albuquerque \\ Escola Superior de Saúde de Viseu - IPV, Viseu, Portugal \\ Health Sciences Research Unit: Nursing (UICISA: E) \\ cmalbuquerque@gmail.com \\ Carla Correia \\ Centro Hospitalar Tondela Viseu, ESSV (Student) Viseu, Portugal \\ carlota.isa@gmail.com \\ Sara Oliveira Albuquerque \\ Student of Medicine \\ sara.r.o.albuquerque@gmail.com
}

Recepción Artículo: 22 octubre 2021

Admisión Evaluación: 22 octubre 2021

Informe Evaluador 1: 23 octubre 2021

Informe Evaluador 2: 24 octubre 2021

Aprobación Publicación: 24 octubre 2021

\begin{abstract}
Objectives: To determine the adherence to physical activity among people with type 2 diabetes Methods: Quantitative, cross-sectional, nonexperimental, descriptive, and correlational study, with a sample of 102 people suffering from type 2 diabetes whose age ranged between 40 and 85 years. Most of the participants were male (51.96\%). The evaluation protocol included a sociodemographic and clinical questionnaire, Diabetes Self-Care Scale(1) and the Diabetes Knowledge Questionnaire(2). The HbA1c clinical parameter was used to directly assess adherence. Results: The self-care activity in which respondents showed higher level of involvement was glucose monitoring that had an average participation of 5.73 days per week. Inversely, participants did not seem interested in physical activity. In this sort of activity participation amounted to 1 mere day per week on average. The study also showed that people with type 2 diabetes show minimal knowledge of areas related to the identity of the illness, its causes, complications, and treatment. $53.9 \%$ of the respondents did not recognise the role played by physical exercise in the treatment of their condition. Conclusion: Reducing the incidence of this disease is an imperative and preventive measure must be implemented to prevent the appearance of the problem, especially for people at higher risk. Among all the possible measures to be implemented, special focus will have to be placed on physical activity and weight loss. Physical activity has a direct impact on the control of the disease through the reduction of $\mathrm{HbA} 1 \mathrm{c}$ levels, but its influence is also evident in other parameters, like weight loss, prevention of risk factors for cardiovascular diseases and it also plays a crucial role in increasing quality of life.
\end{abstract}

Keywords: diabetes; physical exercise; adherence. 


\section{RESUMEN}

Adherencia a la actividad física en personas con diabetes tipo 2.0bjetivos: Determinar la adherencia a la actividad física en personas con diabetes tipo 2 Métodos: Estudio cuantitativo, transversal, no experimental, descriptivo y correlacional, con una muestra de 102 personas con diabetes tipo 2 cuya edad osciló entre 40 y 85 años. La mayoría de los participantes eran hombres (51,96\%). El protocolo de evaluación incluyó un cuestionario sociodemográfico y clínico, la Escala de Autocuidado de la Diabetes(1) y el Cuestionario de Conocimiento de la Diabetes(2). El parámetro clínico HbA1c se utilizó para evaluar directamente la adherencia. Resultados: La actividad de autocuidado en la que los encuestados mostraron mayor grado de implicación fue la monitorización de la glucosa que tuvo una participación media de 5,73 días a la semana. A la inversa, los participantes no parecían interesados en la actividad física. En este tipo de actividad, la participación ascendía a un mero día a la semana en promedio. El estudio también mostró que las personas con diabetes tipo 2 muestran un conocimiento mínimo de las áreas relacionadas con la identidad de la enfermedad, sus causas, complicaciones y tratamiento. El 53,9\% de los encuestados no reconoció el papel que juega el ejercicio físico en el tratamiento de su condición. Conclusión: Reducir la incidencia de esta enfermedad es un imperativo y se debe implementar una medida preventiva para evitar la aparición del problema, especialmente para las personas de mayor riesgo. Entre todas las posibles medidas a implementar, habrá que poner especial énfasis en la actividad física y la pérdida de peso. La actividad física tiene un impacto directo en el control de la enfermedad a través de la reducción de los niveles de HbA1c, pero su influencia también es evidente en otros parámetros, como la pérdida de peso, la prevención de factores de riesgo de enfermedades cardiovasculares y también juega un papel crucial en el aumento de la calidad de vida.

Palabras clave: diabetes; ejercicio físico; adherencia

\section{INTRODUCTION}

Type 2 diabetes is one of the major public health problems worldwide, not only because of the growing number of people affected, but also because of the disability and premature mortality caused by the disease, and of the costs involved in its treatment and prevention. It is a fast-spreading chronic disease and may eventually become one of the biggest pandemics of our time.

World Health Organization(3) argues that diabetes and its complications have an important economic impact on patients, but also on their families and on the countries' healthcare systems, warning that there were 422 million people with diabetes in 2014 and predicting that the number of deaths caused by diabetes will double between 2005 and 2030. The reports show that its prevalence increases with age and affects both genders. The International Diabetes Federation reports that there will be over 425 million adults living with diabetes in 2017. By 2045 this number will rise to 693 million(4).

The Portuguese reality is also cause for concern. This disease is increasingly frequent in our society, and its incidence increases with age and affects both genders. In 2015, its prevalence among the Portuguese population aged between 20 and 79 (7.7 million individuals) was 13.3\%, i.e. over 1 million Portuguese adults included in this age group were living with diabetes(5).

Even though the exact causes of diabetes are not yet fully known, there are several important modifiable risk factors. The most important are obesity, physical inactivity and poor dietary habits .(4) Over the last few decades there have been major changes in people's lifestyles. Theses transformations are taking place mainly in developed countries, but are also happening in developing countries and have led to the proliferation of sedentary behaviours. Sedentarism associated with overweight and abdominal obesity increases the risk of developing this disease (6).

It has been suggested that there is a relationship between obesity and the increase in insulin resistance in individuals with a high accumulation of abdominal fat(7), and is regarded as the major precursor of inflammatory, metabolic and hemodynamic changes that may lead to the development of metabolic syndrome (8). Visceral obesity increases around $300 \%$ between 25 and 65 , increasing the risk of developing type 2 diabetes and cardio- 
vascular diseases, even in adults whose body mass index is classified as normal(9). That way, physical activity and other interventions whose aim is to achieve metabolic control, namely the maintenance of body weight and the reduction of abdominal fat, are important for the prevention of chronic complications in people with type 2 diabetes.

Regular physical activity is an important therapeutic tool to achieve metabolic control. It not only helps prevent the disease or control its evolution, but also influences the improvement of physical fitness, hemodynamic changes, and changes in body weight, which results in an improvement in insulin absorption(7,8). Additional benefits of regular physical activity are related to the emotional, psychic, and social spheres as it often represents a strategy against loneliness and self-exclusion.

Epidemiological studies have shown a strong relationship between physical inactivity, the emergence of chronic complications, and the development of multiple cardiovascular risk factors for individuals with type 2 diabetes $(9,10)$. Physical inactivity is recognised as one of the predictors of mortality among individuals with type 2 diabetes (11). Although physical activity offers an essential and effective therapeutic intervention to control and prevent type 2 diabetes, its effectiveness relies on regular practice(12).

Regular physical activity, such as walking, is an effective strategy to control abdominal obesity and studies have showed that $66 \%$ of individuals with excessive abdominal fat have low level of physical activity $(13,14)$. As far as public health is concerned, this information is important because since walking is the elderly's favourite physical activity(14) convincing them to engage in such an activity will be easier than trying to convince them to try other sports. In addition, implementing such strategies is much cheaper since walking does not require special equipment or setting.

The beneficial effects of adherence to regular physical activity have become evident and can help raise health providers' awareness for the risk of physical inactivity, and reinforce the prescription of physical activity as a complement to pharmacological therapy in the control and treatment of diabetes and of its subsequent complications. Therefore, adherence to treatment has become a key element in the control of type 2 diabetes and consequently in the prevention of its consequences.

Despite the success of medication and of healthcare strategies provided to people with diabetes, the reduction of morbidity and mortality rates, in epidemiological terms, is far from acceptable and nonadherence to treatment is considered one of the main causes of this failure(15).

Adherence rates are actually higher among people with acute illnesses compared to those with chronic conditions. It's hard for people with diabetes to accept the long-term treatment they were prescribed because they have to adopt new habits and behaviours that will affect their eating habits and the way they embrace physical activity(16).

Studies show that low adherence to treatment reduces its benefits, causes constant adjustments in medication due to the lack of positive response to treatment, and increases costs, hospitalization fees and treatment of complications, leading to a decrease in quality of life (17).

Adherence to physical activity may be influenced by many factors or circumstances. One of those factors is that in many cases people with diabetes do not realize how important this adherence is and are not aware of the consequences of non-adherence. The variety of inaccurate beliefs and a poor level of health literacy contribute to the existence of a rather unbalanced view of the therapeutic plan for diabetes and people tend to underestimate the consequences of non-adherence (18). Adherence to self-care is crucial in the management of this chronic disease, and it includes not only taking the medication as prescribed and following the dietary guidelines provided, but also adopting changes in lifestyle, particularly in the practice of physical activity.

The levels of adherence to physical activity are rather poor: a research study recently carried out claimed that only $39 \%$ of adults with diabetes were physically active, when the adherence rate among adults who do not suffer from diabetes is $58 \%$. (11) The massive therapeutic value of physical activity is undermined by the inability of most patients to implement and maintain changes in their lifestyles if they are not provided with constant medical 
supervision. Adherence to treatment among patients with type 2 diabetes is strongly influenced by the patient's level of knowledge, which includes not only what they know or do not know, but also inaccurate misconceptions, beliefs, and assumptions (19). Structured and patient-oriented educational plans play a pivotal role in increasing knowledge, levels of adherence, and metabolic control (20).

There are several studies that prove that prevention of type 2 diabetes requires patients to change the way they live and behave. On the other hand, evidence clearly shows that even when people know what to do or even what they want to do, they simply do not adopt adherence behaviors. People must be provided with the right kind of education and knowledge and with the tools and competences they need to know how to deal with their disease, which will in turn allow them to be autonomous and optimize their metabolic control.

\section{RESEARCH OBJECTIVES}

The objectives of this study are to identify the levels of knowledge that people with insulin-treated type 2 diabetes have of the relationship that exists between physical activity and diabetes, to determine adherence to physical activity and to verify the impact of adherence to physical activity on glycemic control.

\section{SAMPLE}

Sample of 102 people with insulin-treated type 2 diabetes who attend metabolism consultations at the Diabetes Unit of the Tondela Viseu Hospital Centre. Most of the participants were male (51.96\%) and their age ranges between 40 and 85 years.

\section{METHODOLOGY}

Quantitative, cross-sectional, nonexperimental, descriptive, and correlational study, with a The evaluation protocol included a sociodemographic and clinical questionnaire to collect data on the patients' clinical background, a Diabetes Self-Care Scale(1) , a multidimensional scale composed of 6 dimensions and whose reliability was analysed through a Cronbach's Alpha of 0.76 . Each dimension is referred to as a factor and is comprises six dimensions, the number of days per week was the parameter set to assess self-care. The Diabetes Knowledge Questionnaire(2) internal consistency was determined by a Cronbach's Alpha of 0.87 . The HbA1c clinical parameter was used to directly assess adherence.

\section{RESULTS}

The population who took part in our study is between 40 and 85 years old, with a mean age of 63.24 years, a standard deviation of 10.47 and a coefficient of variation of $16.56 \%$. The mean age for men, 62.77 years, is lower than for women, 66.73 years.

Most of the respondents are married (75.5\%), although the group composed of widowers/widows (18.7\%) is also quite representative; they live mainly in rural areas (66.7\%). $50.0 \%$ of them were living at the time with their spouse/partner and $1.0 \%$ were living in institutions. $8.8 \%$ of the individuals from our sample did not go to school, and most of them (52.9\%) completed the primary education, $18.7 \%$ of them left school before entering secondary school. Most of our respondents are retired (56.9\%). $24.5 \%$ of them are still professionally active individuals and $36.0 \%$ of them have commerce-related jobs. According to the clinical profile of the sample, respondents have been living with the disease for 15.3 years on average. The highest average time is 16.39 years and refers to female participants who also register the highest average time (6.74 years) of insulin administration.

Most of the subjects, $54.90 \%$ have relatives with diabetes. The highest percentage $(57.14 \%)$ is found among women. When asked about the number of times they had to be hospitalized, $91.2 \%$ of the respondents reported no hospitalizations in the last 3 months. Among the diabetic patients hospitalized ( $8.8 \%)$, the highest rate of hospitalization episodes occurred among male patients (9.4\%).

All the respondents show acute and chronic complications. Retinopathy is the most common $(30.06 \%)$ and affects $33.75 \%$ of women and $26.51 \%$ of men. Cardiovascular disease was reported by $24.54 \%$ of the subjects 
and the highest incidence of the disease is found among female participants (27.50\%). Amputation is the least common complication, $1.23 \%$.

According to the values of the HbA1c clinical parameter, $42.2 \%$ of the 102 surveyed subjects reported an adequate glycemic control ( $\mathrm{HbA1c}$ between 0 and $7.9 \%)$. Female respondents showed better glycemic control, $44.9 \%$, however chi-square test value does not show statistically significant differences ( $x 2=0.291 ; p=0.590$ ).

Regarding self-care, evidence showed that people with diabetes are highly concerned with continuous glycemia monitoring, which they do 5.73 days per week on average, with their general diet (5.07 days/week), their medication intake (6.85 days/week), specific diet (4.09 days/week) and foot care habits (3.85 days/week). Physical activity seems to be the self-care activity in which patients are less involved: participants claim they take part in physical activities only 1 day per week on average.

In the survey, respondents show extended knowledge of diabetes (41.2\%). Men showed greater knowledge than women. However, knowledge deficit was evident in areas related to the identity of the disease, its causes, the complications it may cause and to its treatment. Medication is considered by $78.4 \%$ of the subjects as the most important component in the treatment of diabetes, whereas 53.9\% did not recognise physical exercise as a part of the treatment.

The relationship between adherence to treatment and self-care practices was assessed with the application of simple linear regression (Table 1). The results obtained showed slight statistical significance between factor 3 and adherence to treatment $(p=.035)$ and between factor 6 and adherence to treatment $(p=.035)$, but these are negative correlations, which means that the greater the individual's weekly involvement in these activities, the lower the $\mathrm{HbA1C}$ value, and therefore the adherence to treatment will be more significant. Factors $1,2,4$ and 5 do not have any statistically significant association, but there seem to be negative correlations, which means that the greater the individual's involvement in these self-care activities, the lower the HbA1c value and consequently the higher the adherence to treatment.

Table 1. Results of the Simple Linear Regression: adherence to treatment according to self-care practices

\begin{tabular}{l|c|c}
\hline \multicolumn{1}{c|}{ Self-care } & $\mathrm{r}$ & $\mathrm{p}$ \\
\hline Factor 1 - General diet &,- 180 &, 070 \\
\hline Factor 2 - Foot care habits &,- 137 &, 171 \\
\hline Factor 3 - Glycemia monitoring &,- 209 &, 035 \\
\hline Factor 4 - Physical activity &,- 163 &, 102 \\
\hline Factor 5 - Medication &,- 110 &, 272 \\
\hline Factor 6 - Specific diet &,- 208 &, 035 \\
\hline
\end{tabular}

The analysis of the relationship between knowledge and adherence showed slightly significant negative correlation ( $r=-0.204 ; p=0.040$ ), which indicates that the higher the level of knowledge, the lower the patients' HbA1c values will be , and the higher the adherence will be as well.

\section{DISCUSSION}

In this study, self-care activities related to diabetes were assessed using the Diabetes Self-Care Activities Scale.(1) We found out that medication intake was the dimension in which the participants developed more selfcare activities on a daily basis, i.e., the participants claimed that they have been taking the prescribed medication correctly 6.85 days a week, on average. Physical activity, on the other hand, was the dimension to which the sub- 
jects seem to attach less importance since they only engaged in physical activities one day per week. These results are in line with the study conducted by Loureiro that shows that scores related to healthy eating habits and physical activity are very low(21).

Management of the therapeutic regimen in type 2 diabetics can be very complex: following the right diet and exercising are the self-care activities that Portuguese diabetics find more difficult to comply with in their everyday life. This problem is hard to overcome because family and friends often fail to understand the importance of fully adhering to the diet and exercise plan defined. The fact that medical treatment is often perceived as a restrictive imposition and the importance of changing lifestyles in diabetes control are some of the barriers to adherence.

As for their knowledge of diabetes, the sample showed poor knowledge in areas related to the identity of the disease, its causes, and treatment. $78.4 \%$ of the surveyed subjects considered medication to be the most important component in diabetes control and treatment and $53.9 \%$ of them did not recognise the vital role played by physical exercise in the treatment of the disease. These results are in line with other Portuguese research studies that show that treatment is the area diabetics seem to know more about whereas dimensions such as causes and identity of the disease are those where diabetics show poorer knowledge(22).

Another international research study, whose aim was to determine the level of knowledge of 96 type 2 diabetics, concluded that they also show poor knowledge in the treatment dimension, since only $4.2 \%$ of them recognized that adopting a healthy eating plan and engaging in physical activity was an integral part of the treatment (23).

The results of our research and those of the other studies referred show that patients have poor knowledge of some dimensions of the disease. Nonetheless, they all seem to agree that in the face of the disease individuals have to develop competences that will allow them to manage their condition, its symptoms, and their limitations and to control it in a way that it can become a part of their life and of their life habits.

The daily treatment of diabetes requires a complex and demanding therapeutic regimen whose aim is to obtain a glycemic profile closer to what is considered normal. Adherence to this therapeutic regimen is difficult as it implies a multiplicity of daily self-care behaviours. To study adherence to treatment in diabetes, one needs to understand that there are several important self-care habits that are vital to the treatment, such as: dietary behaviour, exercise, medication, glucose monitoring and foot care. In our study the correlations between adherence to treatment and self-care, glucose monitoring and specific diet show the presence of slightly significant negative associations $(p<0.05)$.

Correlations between adherence to treatment and other self-care actions show statistically non-significant negative associations. This means that glycemia monitoring and specific diet are variables that influence $\mathrm{HbA1C}$ values but inversely, i.e. the greater the individual's involvement in glycemia monitoring and specific diet is, the lower the $\mathrm{HbA1C}$ value will be, and the higher the adherence will be. The remaining self-care actions, such as general diet, foot care, physical activity and medication intake do not result in statistically significant associations, but will establish negative associations instead, which leads us to infer that the greater the patient's adherence to activities related to these self-care actions, the lower the HbA1c value will be and consequently the higher the adherence to treatment will be either.

There are few studies focusing on the relationship between self-care practices of diabetics and the HbA1c value we used in our study as an indicator of adherence to treatment. Self-care practices themselves are commonly used to measure adherence to treatment which makes it difficult to compare our results with those obtained in other research studies. We can however point out that it is widely acknowledged that patients have a poor adherence when facing recommendations involving physical activity. The beneficial effects of regular exercise in improved glycemic control in patients with type 2 diabetes mellitus are relatively well documented in the literature. A meta-analysis study (24) covering 14 experimental studies clearly showed the significant effect of physical exercise in the improvement of glycemic control. The authors found a $0.66 \%$ reduction in HbA1c after the practice of physical exercise. However, adherence to this component of treatment is generally insufficient to generate adequate glycemic control and poses a major challenge for health providers. 


\section{CONCLUSION}

Of all the dimensions of self-care, physical activity was the dimension to which the participants seem to attach less importance and their weekly involvement in this kind of therapy was found to be very weak. As for the respondents' knowledge of diabetes, they showed poor knowledge in areas related to the identity of the disease, its causes and treatment, and $53.9 \%$ of respondents did not recognise the important role played by physical exercise in the treatment of the disease.

The study also concluded that the higher the adherence to treatment, or in other words, the greater the involvement of the patient in activities related to physical activity is, the lower the HbA1c value will be.

\section{BIBLIOGRAPHIC REFERENCES}

1. Bastos, F., Severo, M., \& Lopes, C. (2007). Propriedades psicométricas da escala de autocuidado com a diabetes traduzida e adaptada. Acta Médica Portuguesa. 20 (1):11-20.

2. Bastos, F. (2014). Adesão e gestão do regime terapêutico do diabético tipo 2. Dissertação de Mestrado. Porto: FMUP.

3. Wordl Health Organization (2016). Global report on diabetes. Geneva; WHO . Available from: http://apps.who.int/iris/bitstream/handle/10665/204871/9789241565257_eng.pdf;jsessionid=D6B9F9754A 2B13ECE08C918B6COF4EC1? sequence $=1$

4. Cho. N., Shaw, J., Karuranga, S., Huang, Y., Rocha Fernandes ,J., Ohlrogge, A., \& Malanda, B. (2018). IDF Diabetes Atlas: Global estimates of diabetes prevalence for 2017 and projections for 2045. Diabetes Research and Clinical Practice. 138:271-81. https://doi.org/10.1016/j.diabres.2018.02.023

5. Sociedade Portuguesa de Diabetologia (2015). Diabetes: Factos e Números - 0 Ano de 2014 - Relatório Anual do Observatório Nacional da Diabetes 2015. Lisboa: Letra Solúvel. http://spd.pt/images/ond_2015.pdf

6. Lima, A., Araújo, M., Freitas, R., Zanetti, M., Almeida, P., \& Damasceno, M. (2014). Fatores de risco para diabetes mellitus tipo 2 em universitários: associação com variáveis sociodemográficas. Revista LatinoAmericana de Enfermagem. 22(3):484-490. https://doi.org/10.1590/0104-1169.3053.2441

7. Bueno, D., Marucci, M., Gouveia, L., Duarte, Y., \& Lebrão, L. (2017). Abdominal obesity and healthcare costs related to hypertension and diabetes in older adults. Revista de Nutrição. 30(2):209-218. https://doi.org/10.1590/1678-98652017000200006

8. Barroso, T., Marins, L., Alves, R., Gonçalves, A., Barroso, S.; \& Rocha, G. (2017). Association of Central Obesity with The Incidence of Cardiovascular Diseases and Risk Factors. International Journal of Cardiovascular Sciences. 30(5): 416-424. http://dx.doi.org/10.5935/2359-4802.20170073

9. Albarello, R.A., Boufleur Farinha, J., Reckelberg Azambuja, C., \& Lopes dos Santos, D. (2017). Efeitos do treinamento resistido sobre o perfil lipídico de indivíduos com síndrome metabólica. Revista Andaluza de Medicina del Deporte. 10(3): 142-146. https://www.redalyc.org/articulo.oa?id=323352592010

10. Kolchraiber, F., Rocha, J., César, D., Monteiro, 0., Frederico, G., \& Gamba, M. (2018). Nível de atividade física em pessoas com diabetes mellitus tipo 2. Revista Cuidarte, 9(2): 2105-2116. https://doi.org/10.15649/cuidarte.v9i2.512

11. Balducci, S., D’Errico, V., Haxhi, J., Sacchetti, M., Orlando, G., Cardelli, P., Di Biase, N., Bollanti, L., Conti, F., Zanuso, S., Nicolucci, A., Pugliese, G., \& Italian Diabetes and Exercise Study 2 (IDES_2) Investigators (2017). Level and correlates of physical activity and sedentary behavior in patients with type 2 diabetes: A cross-sectional analysis of the Italian Diabetes and Exercise Study_2. PloS one, 12(3), e0173337. https://doi.org/10.1371/journal.pone.0173337

12. Mendes, R., Sousa, N., Reis, V., \& Themudo Barata, F. (2011). Programa de Exercício na Diabetes Tipo 2. Revista Portuguesa de Diabetes. 6 (2): 62-70. http://www.revportdiabetes.com/wpcontent/uploads/2017/10/RPD-Vol-6-n\%C2\%BA-2-Junho-2011-Artigo-Original-p\%C3\%A1g-62-70.pdf

13. Bueno, D., Rosa, C., Codogno, J., Junior, I., \& Monteiro, H. (2013). Nível de atividade física, comorbidades 
e idade de pacientes hipertensos. Motriz Revista de Educação Física, 19(3 suppl): S16-S24. https://doi.org/10.1590/S1980-65742013000700004

14. Marquez, D. X., Hoyem, R., Fogg, L., Bustamante, E. E., Staffileno, B., \& Wilbur, J. (2011). Physical activity of urban community-dwelling older Latino adults. Journal of physical activity \& health, 8 (Suppl 2): S161S170. https://pubmed.ncbi.nlm.nih.gov/21918229/

15. Faria, H., Santos, M., Arrelias, C., Rodrigues, F., Gonela, J., Teixeira, C., \& Zanetti, M. (2014). Adherence to diabetes mellitus treatments in family health strategy units. Rev ESC Enferm USP. 48(2):254-260. https://doi.org/10.1590/S0080-623420140000200009

16. Vilas-Boas, L., Foss, M., Freitas, M., Torres, H., Monteiro, L., \& Pace, A. (2011). Adesão à dieta e ao exercício físico das pessoas com diabetes mellitus. Texto Contexto Enfermagem. 20(2):272-279. https://doi.org/10.1590/S0104-07072011000200008

17. Lima, D., Moreira, T., Borges, J., \& Rodrigue, M. (2016). Association Between Treatment Compliance and Different Types of Cardiovascular Complications in Arterial. Texto Contexto Enfermagem. 25(3):1-9. https://doi.org/10.1590/0104-07072016000560015

18. Wild H. (2012). The economic rationale for adherence in the treatment of type 2 diabetes mellitus. The American Journal of Managed Care, 18(3 Suppl), S43-S48. https://ajmc.S3.amazonaws.com/_media/ _pdf/A405_12apr_Wild_S43toS48.pdf

19. Campbell, R. K. (2012). Recommendations for improving adherence to type 2 diabetes mellitus therapyfocus on optimizing insulin-based therapy. The American journal of managed care, 18(3 Suppl), S55-S61. https://pubmed.ncbi.nlm.nih.gov/22558943/

20. Caetano, I., Santiago, L., \& Marques M. (2018). Impact of written information on control and adherence in type 2 diabetes. Revista Associação Med Bras. 64(2):140-1477. https://doi.org/10.1590/18069282.64 .02 .140

21. Loureiro, I. (2017). Adesão ao regime terapêutico da diabetes. Rev Port Diabetes. 2(2):18-21. http://www.revportdiabetes.com/journals-archive/

22. Correia de Sousa, M., Grilo, R., \& McIntyre, T. (2008). Conhecimento do diabético sobre a doença e a repercussão no tratamento. Revista Brasileira em Promoção da Saúde, 21(4): 281-289. https://www.redalyc.org/articul0.0a?id=40811508009

23. Okolie, V., Ehiemere, O., Iheanacho, N., \& Kalu-Igwe, I., (2009). Knowledge of diabetes management and control by diabetic patients at Federal Medical Center Umuahia Abia State, Nigeria. International Journal of Medicine and Medical Sciences. 1(9):353-58. https://citeseerx.ist.psu.edu/viewdoc/download? doi $=10.1 \cdot 1 \cdot 1029.6808 \&$ rep=rep1\&type $=p d f$

24. Boulé N, Haddad E, Kenny G, Wells G, \& Sigal R. (2001) Effects of exercise on glycemic control and body mass in type 2 Diabetes Mellitus: a meta-analysis of controlled clinical trials. J Am Med Assoc. 286(10):1218-1227. https://doi.org/10.1001/jama.286.10.1218 